\title{
Corrigendum
}

\section{Competitive Learning in Yardstick Competition: Testing Models of Policy Diffusion With Performance Data - Corrigendum}

\author{
HUGH WARD AND PETER JOHN
}

doi:http://dx.doi.org/10.1017/psrm.2013.1, Published by Cambridge University Press 2013.

The authors would like to correct a mistake in the expression below.

The mistake is in expression 1 . This reads

$$
\mathrm{U}_{\mathrm{i}}=\alpha_{\mathrm{i}} \mathrm{p}_{\mathrm{i}}+\sum \mathrm{c}_{\mathrm{ij}}\left(\mathrm{p}_{\mathrm{i}}-\mathrm{p}_{\mathrm{j}}\right)-\left(\kappa_{\mathrm{i}}-\mathrm{p}_{\mathrm{i}}^{2}-\varphi_{\mathrm{i}} \mathrm{p}_{\mathrm{i}}\right) / \sum \mathrm{g}_{\mathrm{ij}} \mathrm{p}_{\mathrm{j}}
$$

Whereas it should have read

$$
U_{i}=\alpha_{i} p_{i}+\sum c_{i j}\left(p_{i}-p_{j}\right)-\left(\kappa_{i} p_{i}^{2}-\varphi_{i} p_{i}\right) / \sum g_{i j} p_{j}
$$

\section{REFERENCE}

Hugh Ward and Peter John. 2013. 'Competitive Learning in Yardstick Competition: Testing Models of Policy Diffusion With Performance Data'. Political Science Research and Methods 1:3-25. doi:10.1017/psrm.2013.1. 